\title{
Scientometric Profile of Dentistry, Oral Surgery \& Medicine Research in India with reference to Web of Science (WoS) citation database during $2007-2016$
}

\author{
Chaman Sab $\mathbf{M}^{1}$; Dharani Kumar $\mathbf{P}^{2}$; B. S. Biradar ${ }^{3}$
}

Research Scholar,Dept. of Studies in Library and Information Science

Kuvempu University, Shankarghatta, Shimoga ${ }^{1}$;

Asst. Professor, Dept. of Studies in Library and Information Science

Kuvempu University, Shankarghatta, Shimoga ${ }^{2}$;

Professor, Dept. of Studies in Library and Information Science

Kuvempu University, Shankarghatta, Shimoga ${ }^{3}$

chamansabm@gmail.com ${ }^{1}$;dr.dharanikumarp@gmail.com ${ }^{2}$; bsbiradar53@rediffmail.com ${ }^{3}$

\begin{abstract}
Objective: This study analyzes the research activities of India in Dentistry, Oral Surgery \& Medicine Research during 20072016, based on the total publication output, its growth rate, quality of papers published and rank of India in the global context. Patterns of international collaborative research output and the major partner countries of India are also discussed. This study also evaluates the research performance of different types of research institutes, universities and research foundations and the characteristics of published literature in Indian and foreign journals. It also analyzes the medical research output by disease and organs. Materials and Methods: The publication data on Dentistry, Oral Surgery \& Medicine has been retrieved by using Web of Science (WoS) database. Results: total number of 2934 publications as indexed in web of science database during 2007-2016. The results show that there insignificant growth in Dentistry, Oral Surgery \& Medicine literature published from India. It may be researcher, institutions or India's collaboration with other countries, in all aspects considerable growth can be observed Conclusion: High quality research in India is grossly inadequate and requires strategic planning, investment and resource support. There is also a need to improve the existing dental education system, which should foster research culture.
\end{abstract}

Keywords: Scientometrics Dentistry, Oral Surgery \& Medicine Research, India, publication output.

\section{INTRODUCTION}

The dentist assumes an important position in the health-care system because he alone can diagnose, intercept, treat, cure or prevent any disease or abnormality of the oral cavity. The primary job of dentist is to educate and motivate the patients to maintain oral hygiene because most of the dental \& periodontal diseases are caused by poor oral hygiene. 
There are various branches of dentistry in developed nations. The prominent ones are- Orthodontics, Periodontics, Pedodontics, Prosthodontics, Endodontics, Oral and Maxillo- facial Surgery, Cosmetic \& Esthetic Dentistry, Oral Pathology, Forensic Dentistry, Oral Medicine, Crown \& Bridge Dentistry, Preventive Dentistry, Operative Dentistry, Implant Dentistry, Community Dentistry.

But in India one may specialize only in the following branches by doing MDS after BDS: (i) Orthodontics: A specialized branch of dentistry that corrects malocclusion and restores the teeth to proper alignment and function with the help of different types of appliances, which may be removable or fixed, (ii) Periodontics: The branch of dentistry that deals with diseases of supporting structures of the teeth, including the gums, and bones, (iii) Pedodontics and Preventive Dentistry: is concerned with dentistry related to dental problems in children with their prevention. It involves application of all measures, which can effectively be used to prevent, intercept, control the progressive advance of already existing dental abnormalities and to promote optimum oral \& general health through education, (iv) Prosthodontics: A specialty of dentistry that involves diagnosis, treatment planning, and fabrication of artificial parts to replace missing teeth and their associated structures, (v) Operative Dentistry and Endodontics: Operative Dentistry deals with the defects of teeth such as abrasion, erosion, attrition, dental caries, hypoplasia, and discoloration. Endodontics deals with injuries or diseases of the pulp or nerves of the tooth by treating them with Root Canal Therapy (RCT). It is estimated that today's general dentist spends 60$80 \%$ of his time dealing with such defects; (vi) Oral and Maxillofacial Surgery: is concerned with the extraction of the teeth, surgery of the oral structures, injuries, deformities of the teeth, jaws, and associated structures, (vii) Oral Pathology: deals with the pathology of the oral cavity. It analyzes the oral tissue samples, salivary secretions, and other related structures to identify causes of oral diseases, (viii) Oral medicine: deals with the medicines used in dental practice, and (ix) Community Dentistry: The science \& art of preventing and controlling dental diseases and promoting dental health through organized community effects. It is concerned with dental health education of public with the help of dental health programs \& researches. (Eghbal et al., 2012 [1]).

India has about 260 dental colleges with a workforce of more than 11000 teaching faculty, an intake of more than 1750 postgraduate students per year and produces approximately 17000 dental graduates per year to cater to the dental needs of the popu- lation. Some colleges offer both B.D.S. and M.D.S. courses while other only either of the two. Apart from graduate and postgraduate courses, some institutes also offer diploma courses of 2 years in dental hygiene and dental mechanics. Dental schools in India fall into one of three major categories: (a) governmental dental schools as a part of governmental supported university system, (b) private dental school affiliated with a government funded university, and (c) private dental school as a part of private university.

The first dental colleges and hospitals in India were opened in 1883. Dr. Rafuddin Ahmed established the first official, fully functional, autonomous dental institution in Calcutta in 1920. This institution offered a diploma of licentiate in dental science (L.D.Sc.) upon successful completion of a two-year program. In 1926, the duration of the institu- tion's program of study increased to 3 years for the L.D.Sc. and to a 4-year program for a bachelor of dental surgery degree (B.D.S.) in 1935. The Indian Dental Association was founded immediately after India gained independence in 1947. The Dental Council of India (DCI) was established as a result of the Dentist Act of 1948, which was intended to regulate dental practice and promote scientific advances. DCI is still the premier governing body of dental education in India. Its responsibilities include the regulation of dental education, profession, and ethics and liaising with the government to obtain administrative approval for dental college and higher educational courses. (Kaur \& Gupta, 2010, [2]).

Dentist can also be involved in researches like finding out the correlation between oral diseases and heart problems, diabetes, and respiratory ailments, causes of oral cancer, etc. Another area of research could be the synthesis and analysis of new dental materials for oral applications or electrical stimulation of the muscles of mastication. One of the most Important requirements of the dental profession is that as a dentist, you keep yourself constantly updated with the latest technologies, treatment methods and materials.

Thus India has a great potential to contribute to dental research. Despite this huge number of patients and dental workforce, our representation in dental research committees and peer reviewed indexed dental literature is negligible. (Gupta and Drawn 2008; Wale et al. 2007; Gupta and Drawn 2005; Kaur and Gupta; 2009; Gupta 2010). 


\section{OBJECTIVES}

The main focus of the study is: (i) to analyze the year wise growth of Indian literature on Dentistry, Oral Surgery \& Medicine (ii) to analyze bibliographic Forms types in Dentistry, Oral Surgery \& Medicine; (iii) to analyze the preferred languages; (iv) to analyze the productivity and quality of 15 major institutions participating in research in dental sciences; (iv) to analyze the pattern of research collaboration and major collaborating partners in dental sciences; and (v) to analyze the productivity and quality of leading 15 authors in research in dental sciences.

\section{RELATED STUDY}

Only few scientometrics studies are undertaken in the field of Dentistry, Oral Surgery \& Medicine in India. Among such studies (Shamim, 2017[3]) studied Bibliometric and scientometric information regarding the trends in dental science articles in medical journals from India is evident in the literature. More recently, the publication trends of oral pathology articles published in a pathology journal from Iran were reported. This study aimed to audit the dental science articles published in 62 issues of The Iranian Journal of Medical Sciences (IJMS) from 2002 to 2015 over a 14-year period. (Kaur \& Gupta, 2010[2]) observed the study examines India's performance based on its publication output in dental sciences during 1999-2008, based on several parameters, including the country annual average growth rate, global publication share \& rank among 25 most productive countries of the world, national publication output and impact in terms of average citations per paper, international collaboration output and share and contribution of major collaborative partners, contribution and impact of select top 25 Indian institutions and select top 15 most productive authors, patterns of communication in national and international journals and characteristics of its 45 high cited papers. The study uses 10 years (1999-2008) publications data in dental sciences of India and other countries drawn from Scopus international multidisciplinary bibliographical database. (Eghbal et al., 2012 [1]). have highlighted study on Iran's 20 -year prospective national vision document, Iran may be seen as the most developed country in science and technology in the region by 2025 . In this report, bibliometric indicators are used to compare the research productivity in endodontics between Iran and 28 selected Asian countries.

\section{MATERIALS AND METHODS}

This study based on Indian publication data in Dentistry, Oral Surgery \& Medicine, retrieved from the Clarivate analytics Web of Science (WoS), Science citation database for the 10 years (2007-2016). Search string used for the data retrieval is SU=(Dentistry, Oral Surgery \& Medicine) Refined by Countries/Territories: India AND Timespan=2007-2016. Databases=SCI-EXPANDED, this search criteria yielded 2934 records. The citations received by papers are considered. The institutional performance was measured on the number of quantitative and qualitative indicators, such as the number of papers, average citation per paper (ACPP), h-index (HI) and share of international collaborative papers (ICP) and share of high cited papers (HCP). It is based on the highest number of papers included that have had at least the same number of citations. 


\section{RESULTS AND DISCUSSION}

4.1. Growth of India's Dentistry, Oral Surgery \& Medicine publications output from 2007 to 2016

Table:.1. Year wise Growth rate of India's Dentistry, Oral Surgery \& Medicine publications output

\begin{tabular}{|c|c|c|c|c|}
\hline Year & TP & TC & ACP & $H$ Index \\
\hline 2007 & 117 & 1443 & $12.33 \%$ & 20 \\
\hline 2008 & 143 & 1851 & $12.94 \%$ & 25 \\
\hline 2009 & 225 & 1951 & $8.67 \%$ & 22 \\
\hline 2010 & 268 & 2166 & $8.08 \%$ & 22 \\
\hline 2011 & 481 & 2346 & $4.88 \%$ & 21 \\
\hline 2012 & 416 & 2081 & $5 \%$ & 18 \\
\hline 2013 & 388 & 1499 & $3.86 \%$ & 16 \\
\hline 2014 & 308 & 1029 & $3.34 \%$ & 14 \\
\hline 2015 & 296 & 619 & $2.09 \%$ & 10 \\
\hline 2016 & 292 & 210 & $0.72 \%$ & 6 \\
\hline
\end{tabular}

$\mathrm{TP}=$ Total Publications, $\mathrm{TC}=$ Total Citations, $\mathrm{ACP}=$ Average citations per Year and $\mathrm{h}-$ Index 
Scientometric Profile of Dentistry, Oral Surgery \& Medicine Research in India with reference to Web of Science (WoS) citation database during 2007 -2016

Figure 1. 3D Scene Chart representing Growth rate of publications in Dentistry

\section{Growth of Dentistry, Oral Surgery \& Medicine Research Output}

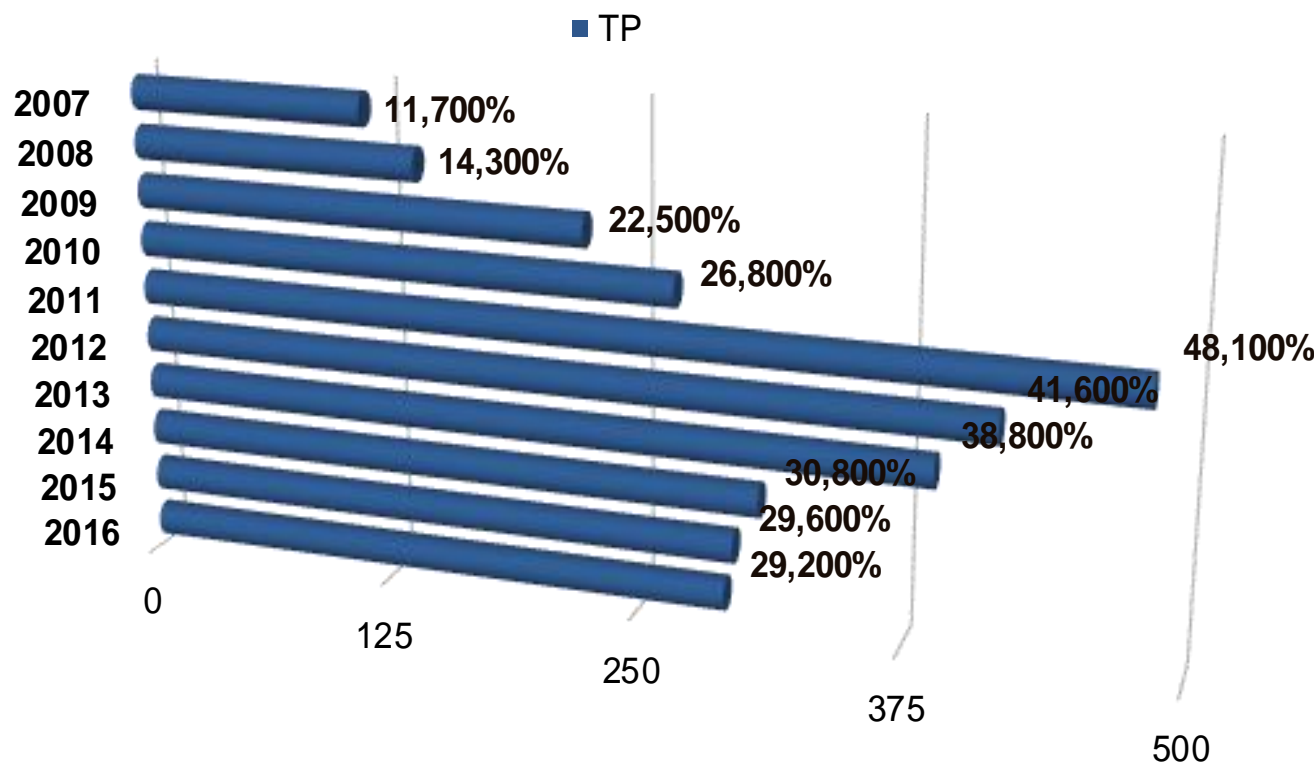

The present study revealed that 2934 papers were published during the period 2007 - 2016 and growth of publications is furnished in Table - 1. It has been observed that during the 2007 - 2016. It is found from table 1 that Highest number of publications $481(48.100 \%)$ were produced in the year 2011. It is followed by $412(41.600 \%)$ in the year of 2012, and lowest publications $117(11.700 \%)$ were published in the year of 2007. While during the period of 2007 to 2011 there steady growth in the research publications and $\mathrm{h}$ - index also a close watch on the publications revealed that during the period, there is a declining trend on equine research as the number of publications is slowly decreasing as the number of publications during 2013 to 2016 . The declining trend needs to be taken care of by the stakeholders of equine research.

\subsection{Bibliographic forms of India's Dentistry, Oral Surgery \& Medicin}

Table. 2. Bibliographic forms of India's Dentistry, Oral Surgery \& Medicine

\begin{tabular}{|l|c|c|}
\hline Document Types & Records & \% of $\mathbf{2 9 3 4}$ \\
\hline Article & 2248 & 15.623 \\
\hline Letter & 258 & 1.793 \\
\hline Review & 194 & 1.348 \\
\hline Meeting abstract & 174 & 1.209 \\
\hline Editorial material & 53 & 0.368 \\
\hline Proceedings paper & 22 & 0.153 \\
\hline Correction & 7 & 0.049 \\
\hline Retracted publication & 2 & 0.014 \\
\hline
\end{tabular}


Figure 2 gives an idea about publications which published in different type of Bibliographic forms documents found in the collected records. It is evidence that the journal is the most preferred medium of all the forms, of the total research literature output in Dentistry, Oral Surgery \& medicine, $76 \%$ is in the form of articles followed by Letters $9 \%$, Reviews $1.348 \%$, Meeting abstract $1.209 \%$, Proceedings papers $0.153 \%$, Corrections $0.49 \%$ and lastly retracted publications $0.014 \%$.

\subsection{Preferred from language wise in Dentistry, Oral Surgery \& Medicine}

The study found that English is the preferred language by the authors of equine research to publish their research papers as $99.93 \%$ (2932) were published in English language and followed by Portuguese 0.069\% (02). The only two languages preferred by the authors.

\subsection{Indian Institutional wise research output}

Fig.: 2; Indian Institutional wise research output

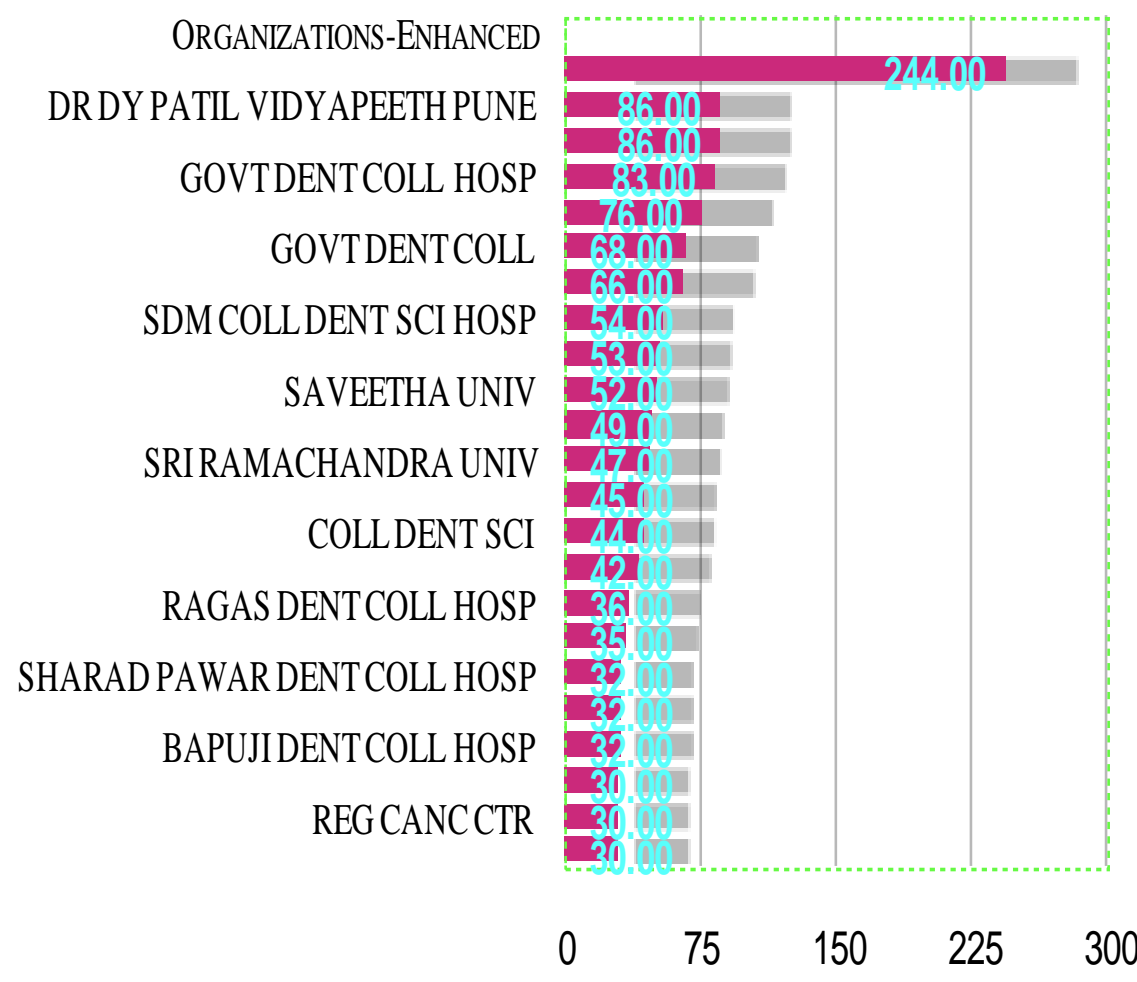

Based on publications output data for India in Dentistry, Oral Surgery \& Medicine, a total of 25 institutions were identified as high productive ones published. These top 25 institutions together contributed 1352 in the total research output by India in Dentistry, Oral Surgery \& Medicine. These institutions along with their publications output are: maniple university (244 papers), Dr DY Patel Vidayapeeth, Pune, All India Institute of Medical Sciences (86 papers), Government Dental college and Hospital Bangalore (83 papers), Government Dental college and Research Institute (76 papers), Government Dental College (68 papers), Tata memorial Hospital Mumbai (66 papers), SDM College of Dental Science and Hospital, Dharwad (54 papers), Amrita Vishwa Vidyapeetham University (53 papers), Saveetha University (52 papers), Maulana Azad memorial Institute of Dental Science, New Delhi (49 papers), Sri Ramachandra University University (47 papers), PGIMER Chandhigrah (45 papers), College of Dental Science, Davanagere (44 papers), AB Shetty Memorial Institute of Dental Science Mangalore (42 papers), Ragas Dental College and Hospital Chennai (36 papers) and remaining 7 institutions were produced 221 publications during the study period 2007 - 2016. 
Scientometric Profile of Dentistry, Oral Surgery \& Medicine Research in India with reference to Web of Science (WoS) citation database during $2007-2016$

\subsection{India's author productivity and quality profile}

Table.3. Rank with highly cited papers in research output of India’s Dentistry, Oral Surgery \& Medicine

\begin{tabular}{|c|c|c|c|c|}
\hline $\begin{array}{l}\text { Rank } \\
\text { with } \\
\text { Citations }\end{array}$ & Titel & Authors & Source & $\begin{array}{l}\text { Vol. Issue \& } \\
\text { Year }\end{array}$ \\
\hline $\begin{array}{l}1 \\
151\end{array}$ & $\begin{array}{l}\text { Smoking interferes with the prognosis of } \\
\text { dental implant treatment: a systematic review } \\
\text { and meta-analysis }\end{array}$ & $\begin{array}{l}\text { Strietzel, } \\
\text { FP; et al }\end{array}$ & \begin{tabular}{|l|}
\multicolumn{1}{|c|}{ Journal of } \\
clinical \\
periodontology
\end{tabular} & 34.06 .2007 \\
\hline $\begin{array}{l}2 \\
137\end{array}$ & $\begin{array}{l}\text { Pathogenesis of oral lichen planus - a } \\
\text { review }\end{array}$ & $\begin{array}{l}\text { Roopashre } \\
\text { e, MR; et al }\end{array}$ & \begin{tabular}{|} 
Journal of \\
oral pathology \\
$\&$ medicine
\end{tabular} & 39.10 .2010 \\
\hline $\begin{array}{l}3 \\
103\end{array}$ & \begin{tabular}{|} 
Efficacy of revascularization to induce \\
apexification/apexogensis in infected, \\
nonvital, immature teeth: A pilot clinical study
\end{tabular} & Shah, N & $\begin{array}{r}\text { Journal of } \\
\text { endodontics }\end{array}$ & 34.08 .2008 \\
\hline $\begin{array}{l}4 \\
94\end{array}$ & $\begin{array}{c}\text { Orthodontic pain: from causes to } \\
\text { management - a review }\end{array}$ & V Krishnan, & \begin{tabular}{|l|}
\multicolumn{2}{|c|}{ European } \\
journal of \\
orthodontics
\end{tabular} & 29.02 .2007 \\
\hline $\begin{array}{l}5 \\
87\end{array}$ & $\begin{array}{c}\text { On a Path to Unfolding the Biological } \\
\text { Mechanisms of Orthodontic Tooth Movement }\end{array}$ & \begin{tabular}{|rr} 
& Krishnan, \\
$V$ & $\&$ \\
Davidovitch, $\mathrm{Z}$
\end{tabular} & $\begin{array}{r}\text { Journal of } \\
\text { dental research }\end{array}$ & 88.07 .2009 \\
\hline $\begin{array}{l}6 \\
77\end{array}$ & $\begin{array}{l}\text { Rote of tobacco smoking, chewing and } \\
\text { alcohol drinking in the risk of oral cancer in } \\
\text { Trivandrum, India: A nested case-control } \\
\text { design using incident cancer cases }\end{array}$ & $\begin{array}{r}\text { Muwonge, } \\
\mathrm{R} \text {; et al }\end{array}$ & $\begin{array}{r}\text { Oral } \\
\text { oncology }\end{array}$ & 44.05 .2008 \\
\hline 73 & $\begin{array}{l}\text { Corrosion behaviour of Ti-15Mo alloy for } \\
\text { dental implant applications }\end{array}$ & Kumar, S ; & $\begin{array}{c}\text { Journal of } \\
\text { dentistry }\end{array}$ & 36.07 .2008 \\
\hline $\begin{array}{l}8 \\
62\end{array}$ & $\begin{array}{l}\text { Effect of periodontal therapy on } \\
\text { pregnancy outcome on women affected by } \\
\text { periodontitis }\end{array}$ & 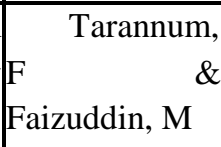 & $\begin{array}{r}\text { Journal of } \\
\text { periodontology }\end{array}$ & 78.11 .2007 \\
\hline $\begin{array}{l}9 \\
63\end{array}$ & $\begin{array}{l}\text { Clinical Effect of Subgingivally Delivered } \\
\text { Simvastatin in the Treatment of Patients With } \\
\text { Chronic Periodontitis: A Randomized Clinical } \\
\text { Trial }\end{array}$ & \begin{tabular}{|l}
\multicolumn{2}{c}{ Pradeep, } \\
AR \& Thorat, \\
MS
\end{tabular} & 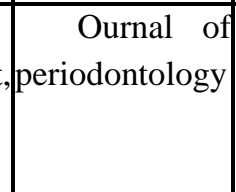 & 81.02 .2010 \\
\hline
\end{tabular}

Table 3 depicts highly cited papers from India in Dentistry, Oral Surgery \& Medicine published in various journal s during 2007 - 2016. Most frequently cited one was "Smoking interferes with the prognosis of dental implant treatment: a systematic review and meta-analysis" with 151 citations written by Strietzel, FP; et al which published in Journal of Clinical Periodontology (2007), P Pathogenesis of oral lichen plans a review with 137 citations written by Roopashree M R and others which published in Journal of Oral Pathology and Medicine (2010), On a Path to Unfolding the Biological Mechanisms of Orthodontic Tooth Movement study with 103 citations written by She N and others which published in Journal of Endodentitics (2008), Orthodontic pain: from causes to management - a review with 94 citations written by Krishna V which published in European Journal of Orthodontics (2007). 


\subsection{Research area wise distribution of publication.}

Table: 4. Research Area wise research output in India's Dentistry, Oral Surgery \& Medicine publications output

Table 4. Shows research area wise distributions of publications on Dentistry, Oral Surgery \& Medicine published 2007 - 2016 according to Web of Science (WoS) database. As already discussed Dentistry, Oral Surgery \& Medicine is playing significant role in many other domains like Oncology, Surgery and Pediatrics many more. Oncology top the list with 331 publications and it is also received; Surgery having 306 publications and Pediatrics having 262 publications.

\subsection{Sources wise distribution of publication}

\begin{tabular}{|c|c|c|}
\hline \multicolumn{1}{|c|}{ Research Areas } & Records & \% of $\mathbf{2 9 3 4}$ \\
\hline Dentistry oral surgery medicine & 2934 & 20.391 \\
\hline Oncology & & \\
\hline Surgery & 331 & 2.3 \\
\hline Paediatrics & 306 & 2.127 \\
\hline Padiology nuclear medicine medical imaging & & \\
\hline Pathology & 262 & 1.821 \\
\hline & 62 & 0.431 \\
\hline Geriatrics gerontology & 56 & 0.389 \\
\hline Materials science & & \\
\hline & 48 & 0.334 \\
\hline & & \\
\hline Eublic environmental occupational health & 8 & 0.056 \\
\hline Engineering & 7 & 0.049 \\
\hline & & \\
\hline & 7 & 0.049 \\
\hline
\end{tabular}


Scientometric Profile of Dentistry, Oral Surgery \& Medicine Research in India with reference to Web of Science (WoS) citation database during $2007-2016$

Table: 5. Source wise research output in India's Dentistry, Oral Surgery \& Medicine publications output

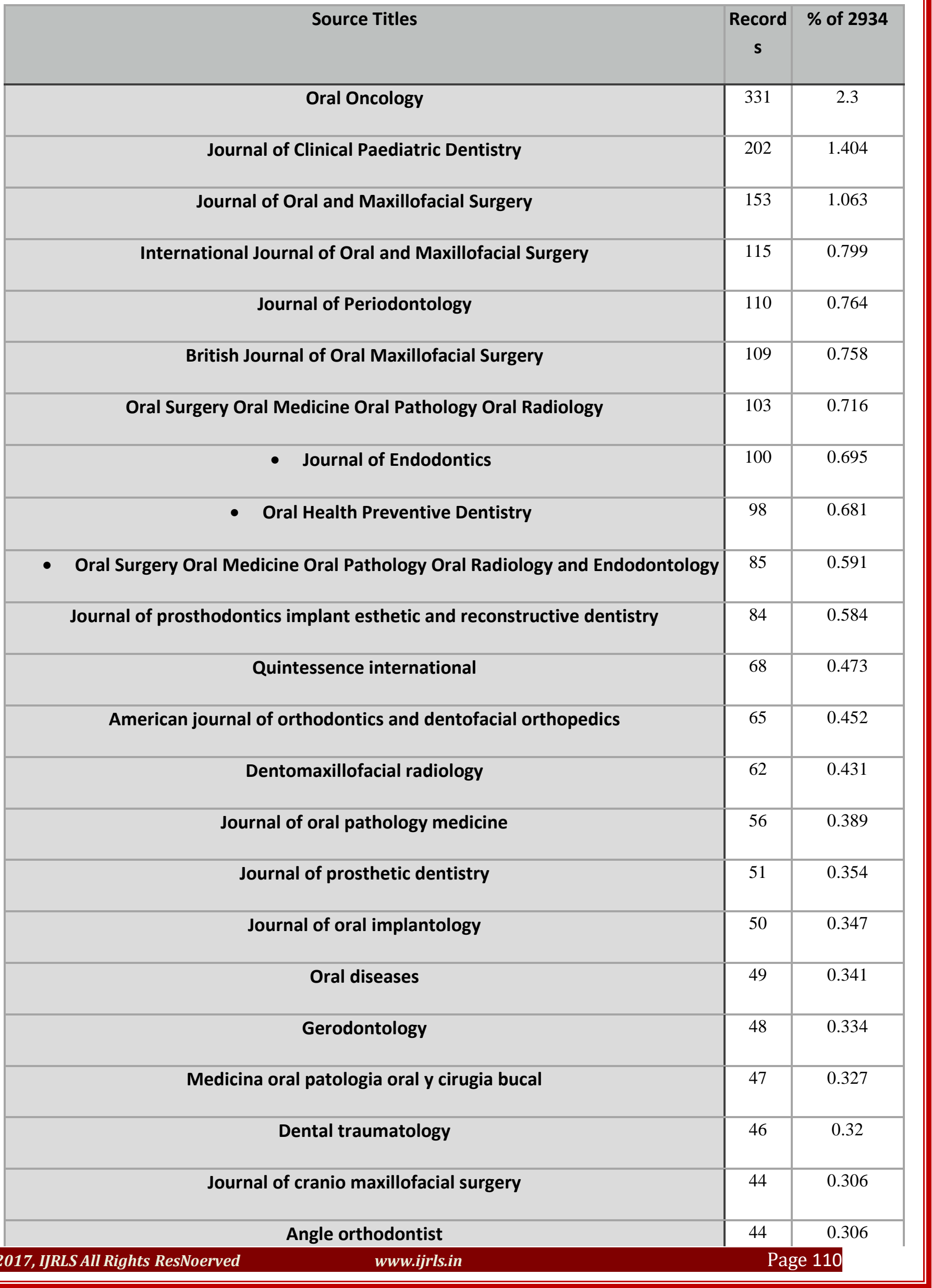


Journals are main source for publishing research work. Table 3 shows top 23 Journals which published papers on India's Dentistry, Oral Surgery \& Medicine during 2007 - 2016 as per Web of Science Citation database. Some journals are Oral Oncology 331 (2.3\%), Journal of Clinical Pediatric Dentistry 202 (1.404\%), Journal of Oral and Maxillofacial Surgery 153 (1.063\%), International Journal of Oral and Maxillofacial Surgery 115 (0.799\%), Journal of Periodontology 110 (0.764\%), British Journal of Oral Maxillofacial Surgery 109 (0.758\%) and lowest articles published in the journal $44(0.306 \%)$ in Journal of Cranio maxillofacial surgery.

\section{Findings}

The findings of the present lead to the following concluding remarks. The Scientometric analysis of the India's Dentistry, Oral Surgery \& Medicine from 2007 - 2016 for period of study. The journals has Finding of growth of publication of Dentistry, Oral Surgery \& Medicine research output brings out the research paper published trend in increasing. The overall study period the highest percentage publication published in 2013.

\section{Conclusion}

Dentistry, Oral Surgery \& Medicine plays a revolutionary part in Medical, present study is an overview of Dentistry, Oral Surgery \& Medicine research in India during 2012-2016. For analyzing gathered data many scientometric techniques has been used. Assessment of research activity is very important get knowledge of present situation in that particular field. After analyzing total number of 2712 publications as indexed in web of science database during 2012-2016. The results show that there insignificant growth in Dentistry, Oral Surgery \& Medicine literature published from India. It may be researcher, institutions or India's collaboration with other countries, in all aspects considerable growth can be observed.

Conclude that dental science research is in poor state of affairs in India, both in terms of output as well as in quality. Therefore, heavy investment is required in terms of R\&D investment from the government to upgrade this field and increase the research output. The government should come out with special schemes to promote R\&D in this area. In order to upgrade quality in research, increase in international collaboration and wider participation in international conferences/seminars may be encouraged for those who have involved in R\&D work.

\section{REFERENCES}

[1]. Eghbal, M. J., Ardakani, N. D., \& Asgary, S. (2012). A scientometric study of PubMed-indexed endodontic articles: A comparison between Iran and other regional countries. Iranian Endodontic Journal, 7(2), 56-59.

[2]. Kaur, H., \& Gupta, B. M. (2010). Mapping of dental science research in India: A scientometric analysis of India's research output, 1999-2008. Scientometrics, 85(1), 361-376. https://doi.org/10.1007/s11192-010-0213-9

[3]. Shamim, T. (2017). Bibliometric analysis of the dental science articles published in the Iranian journal of medical sciences (IJMS) from 2002 to 2015 over a 14-year period. Iranian Journal of Medical Sciences, 42(1), 106-107. https://doi.org/10.1016/j.mjafi.2015.04.009.

[4]. Satyanarayana K.(2017). Final Report of the project on National Mapping of Science: Biomedical Sciences. Information Today and Tomorrow.;19(1):17-21. Available from: h p://i .nissat.tripod.com/ i 2001/nmsbio.htm [Last accessed on July 2017].

[5]. Jain NC.(2008). Growing visibility of Indian Dentistry, Oral Surgery \& Medicine and life science journals in global alerting services. In: H Kretschmer, F Havermann, editors. Proc of WIS 2008, Berlin Fourth Intl Conf on Webometrics, Informatics and Scientometrics and Ninth COLLNET meeting Humboldt-University zu Berlin: Institute for Library and Information science. 2008. Available from: h p://www.collnet.de/ Berlin_2008/Jain WIS gvi.pdf .

[6]. Srivastava D, Diwakar S. Changing face of Indian Medical Research: A Collaboration analysis of papers from SCi (1999 and 2007) in:HKretschmer, F Havermann, editions. Proc of WIS 2008, Berlin Fourth Intel Conf. On Webometrics, Informetrics and Scientometrics and Ninth COLLNET meeting Humboldt-University Zu Berlin: Institute for Library and Information Science; 2008.

[7]. Costas, Rodrigo, Bordons, María.(2011) Do age and professional rank influence the order of authorship in scientific publications? Some evidence from a micro-level perspective. Scientometrics 88:1, 145-161. Online publication date: 19Mar-2011. 
[8]. Mahmudi Z, Tahamtan I, SedghiSh, Roudbari M. (2015). Ranking Iranian biomedical research centers according to Hvariants (G, M, A, R) in Scopus and Web of Science. Medical Journal of the Islamic Republic of Iran, 7 (29). 1-17.

[9]. Bala, Adarsh and Gupa, B.M. (2010). Mapping of India neuroscience research: A Scientometri analysis of research output during 1999-2008. Neurology India 58(1). 35-41.

[10]. N. GovindaRaju (2017). A Scientometric Analysis of International Journal of Information Dissimination and Technology (IJIDT) During 2011-2015. International Journal of Information Dissemination and Technology 7(2) 146150. 